\title{
“O COBRADOR" DE RUBEM FONSECA: A UTOPIA DE UM MARGINAL EM BUSCA DE UMA REVOLUÇÃO SOCIAL
}

Cristiane Sucheski Contin

Especilizanda em Literatura Brasileira e História Nacional - UTFPR

Ângela Maria Rubel Fanini

Doutora em Literatura Brasileira pela UFSC e Professora do Departamento Acadêmico de Comunicação e Expressão da UTFPR, Campus Curitiba.

RESUMO: O presente ensaio visa a analisar o conto "O cobrador" de Rubem Fonseca, abordando seu personagem central que luta para exterminar as classes brasileiras abastadas. Esse personagem faz parte de um grupo de excluídos da sociedade que se revolta com sua situação e tenta resolvê-la pelos caminhos da violência espetacular. Com a leitura do conto é possível compreender a formação desse marginal diante do quadro sócio-econômico do Brasil dos anos 70 e dessa forma a desigualdade social refletida em um ser que atinge o ponto máximo da violência no desejo de mudar a realidade.

Palavras-chave: marginalidade social; sociedade brasileira; Rubem Fonseca; literatura brasileira; o conto.

Para conduzir o personagem Cobrador em sua utópica missão, temos o autor e ex-policial Rubem Fonseca. Em sua profissão, o autor de $O$ cobrador $[i]$ conviveu com diversos tipos de criminosos que mais tarde seriam formalizados literariamente em suas obras. Seus livros estão repletos de assassinos, criminosos, prostitutas e outros seres excluídos da sociedade e imersos na violência do meio urbano. Para COUTINHO[ii]: "Os seus contos [de Rubem Fonseca] (...)oferecem, sobretudo, um quadro da atual sociedade carioca, e acredito que se possa dizer brasileira, um estado de crise". Dessa forma, a matéria para os contos está na sociedade, nas ruas, na proximidade com as mudanças sociais e políticas da história brasileira. Em 1976, Rubem Fonseca tem seu livro Feliz Ano Novo proibido por ser considerado pornográfico, o que o faz imaginar-se uma vítima do Regime Militar. Então usa todo seu arsenal literário para escrever um outro livro de contos que, em 1979, chocaria a sociedade brasileira: $O$ Cobrador.

Direcionando o foco para o conto que dá nome ao livro, "O Cobrador", constatase que a narrativa nos traz a trajetória de um personagem-narrador marcado pelo anonimato e ao mesmo tempo conhecido à medida que representa de certa maneira a classe dos excluídos. Em sua saga de justiça, destrói o consultório de um dentista, atira em um homem em uma Mercedes, mata um executivo e seqüestra um casal da alta sociedade, matando a tiros a mulher e degolando o homem, como via nos filmes e sempre desejou fazer igual. Além disso, ao longo do conto vai compondo uma lista de necessidades que a sociedade lhe "deve": "Estão me devendo comida, buceta, cobertor, sapato, casa" (OC, p.166). Seu ódio aumenta quando assiste a programas televisivos e vê a classe média-alta, exibindo artigos de luxo que não podem ser 
adquiridos por todos.

Em seus envolvimentos amorosos, conhece uma "coroa" que lhe dá abrigo e ouve suas poesias grotescas, porém sem compreendê-las. Em outro momento, finge-se de bombeiro e estupra uma mulher, também da classe média-alta que a princípio reluta em se entregar, mas acaba demonstrando que sentiu prazer com o estupro. Na praia (local de igualdade social, segundo ele) conhece uma bela moça: Ana. Apesar da moça ser rica, mostra-se interessada por ele e ambos começam a ter um relacionamento, apoiados pela proprietária da pensão em que o marginal mora, Dona Clotilde, uma senhora hipocondríaca que nutre por ele um carinho maternal. Ana apóia seus crimes e passa a auxiliá-lo, planejando juntos uma destruição em massa, o que é classificado por eles como um tipo de missão.

Após esse comentário geral sobre o conto é interessante refletir acerca desse personagem Cobrador, sobre o que constitui seu caráter. Pela ausência de biografia, não fica claro o seu passado. Quando ele diz "Cansei de pagar! Agora eu só cobro!" (OC, p.166) causa a impressão de que um dia já foi um cidadão "normal" que pagava suas contas, levando à reflexão acerca de quando e como teria se desencadeado seu desejo de cobrança. Isso poderia ser o resultado de uma tensão latente, talvez há muito tempo, em seu eu atormentado pelas injustiças sociais. Sua profissão também não é esclarecida, apesar do personagem se dizer poeta: "Ela pergunta o que eu faço e digo que sou poeta, o que é rigorosamente verdade".(OC, p.169). Seus versos destacam a desigualdade social, mas são fragmentados como seu próprio pensamento. Além disso, sua relação com o trabalho é ausente e não fica clara a maneira como se sustenta, já que não rouba suas vítimas.

A linguagem utilizada pelo personagem Cobrador, apesar dos palavrões e gírias, demonstra uma certa erudição que pode representar os ideais do próprio autor, Rubem Fonseca, de mostrar a podridão moral da sociedade, misturando essas duas vozes, do narrador marginal e do autor intelectual. De acordo com o que diz Deonísio da SILVA [iii] sobre o ato de narrar nas obras de Rubem Fonseca, seus narradores em primeira pessoa ganham uma espécie de "poder" dentro das tramas, conduzindo o leitor. Ele faz uma espécie de "pacto" com o leitor, confidenciando a ele seus piores segredos e tentando persuadi-lo de sua causa.

O personagem Cobrador tenta transmitir ao leitor a mensagem de que pertence a uma classe social que provavelmente se encaixe entre pobre e miserável e de quem tudo foi retirado. Ao citar "estão me devendo" manifesta seu desejo de recuperar o que the foi roubado, para com isso, quem sabe, adquirir a "normalidade" que tanto se espera na sociedade. Em uma de suas listas, ele inclui também a palavra respeito, ou seja, aquilo que não podem pedir que tenha já que um dia lhe tomaram. A revolta dele para com o mundo surge dessa abstinência de elementos às vezes até supérfluos à sobrevivência, mas tão fundamentais à vida.

Focando o período em que o conto foi escrito, 1979, nota-se que o Brasil passava por uma grave crise social. Com o Golpe Militar de 1964 há a tomada da Presidência pelos militares, que governariam o país até 1985, usando seu poder para estabelecer 
diversas medidas autoritárias. Entre os anos 60 e 70 vários fatores contribuem para a ascensão das classes média e alta: Aumento considerável do PIB (Produto Interno Bruto), crédito facilitado e abertura externa da economia. Assim, constrói-se o chamado "milagre econômico" que beneficiaria a burguesia e achataria os pobres. Entretanto, em 1973, há a chamada "crise do petróleo", os preços aumentam, gerando uma crise econômica mundial que vai se refletir na balança comercial. A renda ganha concentração na mão de poucos e a pobreza aumenta para muitos. Os anos 70 também vão se caracterizar pelas revoltas de operários, organizações sindicais e perseguições militares àqueles que não concordassem com o regime de governo. Esse é um período de grande tensão e desequilíbrio social. O marginal do conto vai ser fruto dessa tensão, representando a revolta das classes pobres. No momento em que esses sentimentos vêm à tona é quando os marginalizados devolvem a violência que sofrem com a miséria e a pobreza multiplicada diversas vezes para a sociedade.

O conto consegue transformar o personagem Cobrador em uma espécie de herói/ anti-herói, exterminando os ricos para vingar os pobres. Isso é o que move esse personagem: lidar com sua situação de marginal, não se conformando a ela, mas mostrando o quanto ela é injusta. Deseja também exibir ao leitor a hipocrisia da sociedade e enquanto executa suas vítimas, vai tecendo críticas terríveis. Detesta os ricos que ostentam o que conseguiram, muitas vezes, de forma desonesta e sua preferência pelo luxo desnecessário. "Ah, certas pessoas pensam que a vida é uma festa".(OC, p.172). Sua revolta é imensa, mas mesmo sendo miserável, em todos os sentidos, o personagem Cobrador mata, mas não rouba. $O$ ato de roubar, segundo ele, estaria destinado àqueles que enriquecem, explorando os menos favorecidos.

O marginal passa por uma enorme angústia existencialista. A opressão da cidade fará com que deseje fugir de tudo e todos e ao mesmo tempo atingi-los. A criminalidade s e transforma em patologia e o personagem Cobrador em um psicopata, um misantropo, alguém completamente avesso à vida em sociedade. "A rua está cheia de gente. Digo, dentro da minha cabeça, e às vezes para fora, está todo mundo me devendo".(OC, p.166). A multidão o irrita, fazendo com que sinta sua impotência diante do mundo, afinal todos, de alguma forma, são seus devedores. Assim, agirá de maneira animalizada, movido pelos instintos, inclusive de sobrevivência, não se importando com regras e muito menos com a religião. Para MARTINEZ [iv]: “Os personagens de Fonseca habitavam - e continuam a habitar - um mundo anterior a Deus, ou no qual Deus é indiferente, ou quem sabe um mundo em que Deus é desnecessário". O marginal parece viver em um mundo prestes a acabar e ele poderia ser uma das bestas do apocalipse.

Essa agonia do homem urbano vem desde os autores naturalistas do século XIX. Em obras de Machado de Assis e Aluísio Azevedo já era possível perceber a ação das cidades sobre os indivíduos, porém segundo SILVERMAN[V] “Nenhum, entretanto, compara-se, com Rubem Fonseca na aspereza contínua com que pinta o drama (tragédia) urbano ou na acidez satírica que lhe provoca o seu mundo torturado".

O autor consegue ridicularizar os problemas dessa "urbe", exagerando-os com 
palavrões. A violência está presente nas ações do conto, mas também na linguagem com que elas se expressam. Para Martinez [vil: "Fonseca instala o medo ou o mal no próprio interior da linguagem, cada uma de suas palavras é como uma nota musical arrancada da sinfonia do mal". Dessa forma, o marginal relata seus feitos, escolhendo um vocabulário que oscila entre o macabro e o lírico, entre o irônico e o trágico e entre o popular e o erudito, desvelando no excesso de sua linguagem a falta de perspectivas.

Em alguns momentos o personagem se mostra tão forte e poderoso: "Onde eu passo o asfalto derrete" (OC, p.173), mas paradoxalmente tão frágil, humilhado: "A mão dele era branca, lisinha, mas a minha estava cheia de cicatrizes, meu corpo todo tem cicatrizes, até meu pau está cheio de cicatrizes" (OC, p.167). Sente-se solitário: "Sou uma pessoa tímida, tenho levado tanta porrada na vida" (OC, p.175). Nessa frase parece estar dialogando em contra-ponto com o "Poema em linha Reta" [viil de um dos heterônimos de Fernando Pessoa: Álvaro de Campos, que em dois de seus versos diz: "Nunca conheci quem tivesse levado porrada./ Todos os meus conhecidos têm sido campeões em tudo". Em ambos percebe-se a sensação de derrota diante dos obstáculos impostos ao ser humano em sua existência em sociedade.

Mas é verdadeiramente no relacionamento homem versus mulher que 0 personagem Cobrador vai revelar seus sentimentos. Sente "pena" da "coroa" com quem mora, realiza parte de sua vingança no estupro da "ricaça" e amor por Ana. Ao longo do conto os atos sexuais são meticulosamente descritos, inclusive por palavrões. O sexo é animalizado e instintivo, herança dos autores naturalistas, que exploraram esse momento em que o homem é tomado por sua "essência", por aquilo que o aproxima dos outros animais. Nos contos de Rubem Fonseca, a cópula não visa à reprodução, mas sim a uma forma de relacionamento social, que muitas vezes só pode ocorrer pelo sexo. Os protagonistas-narradores de Rubem Fonseca tradicionalmente são movidos por seus excessos sexuais como fuga de um mundo insuportável. Dessa forma suas obras são consideradas, em alguns casos, pornográficas e geradoras de polêmicas como Feliz Ano Novo, livro censurado pela ditadura e defendido por COUTINHO[Viii]: "O erotismo e a pornografia que ele [Rubem Fonseca] expõe não são sua invenção, pertencem à vida que o cerca e a todos nós". O próprio Rubem Fonseca falará da pornografia em um de seus contos, “Intestino Grosso":[ix]

\footnotetext{
“Mas quando os defensores da decência acusam alguma coisa de pornográfica é porque ela descreve ou representa funções sexuais ou funções excretoras, com ou sem uso de nomes vulgares comumente referidos como palavrões. O ser humano, como alguém já disse, ainda é afetado por tudo aquilo que o relembra inequivocamente de sua natureza animal. Também já disseram que o homem é o único animal cuja nudez ofende os que estão em sua companhia e o único que em seus atos naturais se esconde de seus semelhantes".
}

Assim, o erótico é capaz de ocupar em conjunto com a violência e a falta de perspectivas o espaço do conto de Rubem Fonseca, mesclando assassinato, estupro e amor. Ao mesmo tempo em que o personagem Cobrador é capaz de cortar a cabeça de um homem e sentir um imenso prazer com isso, pode amar uma mulher e fazer 
desse um momento de grande lirismo.

Em meio a tantos crimes, Ana será um lenitivo para o marginal. Ela é descrita por ele como sendo uma moça fascinante, dona de uma beleza singular e rica, ou seja, ela é exatamente 0 estereótipo daqueles que eram assassinados cruelmente pelo personagem. Mas, desde o momento que a conhece, pensa unicamente em amá-la, jamais a enxerga como um dos seres de quem deveria se vingar. Desse modo, o personagem Cobrador torna-se contraditório, pois parece abrir uma exceção em seus planos, rendendo-se a Ana e dividindo com ela sua vingança.

Ana certamente muda a vida do personagem Cobrador. Antes de conhecê-la, o marginal tinha o desejo alucinado de matar pessoas e se vingar daquilo que the foi tomado, mas ao conhecê-la, com seus conselhos, passa a encarar sua vingança como uma missão. Dessa forma, nota-se a importância da moça nesse processo de transformação pelo qual o personagem Cobrador passa. A moça é rica e fútil, e encontra no projeto de vingança de seu amado um sentido para sua própria existência, comandando a missão conforme seus próprios ideais e subjugando-o. O personagem Cobrador é um marginal por sua pobreza de bens materiais, por pertencer à classe dos excluídos e Ana se torna marginal à medida que anseia pela transcendência de sua rotina vazia: dois opostos sócio-econômicos.

Seu amor por Ana não irá redimi-lo ou levá-lo para o caminho do "bem", mas fará com que descubra em Ana alguém que compartilha de sua ideologia e que será uma parceira perfeita para sua saga justiceira. O que mais encanta o personagem Cobrador a seu respeito é o fato dela não sentir medo dele, sentimento que despertava nas outras mulheres. Porém, de certa forma, nota-se que o marginal tem vestígios de uma espécie de "cavalheirismo", já que demonstra ter respeito, principalmente por essas duas mulheres: Dona Clotilde, a quem ajuda em sua pensão e Ana, por quem se apaixona, as únicas personagens do conto que têm nome. Ele vê nas duas sua proteção frente ao mundo que o perturba, um apoio feminino e maternal que diminui sua sensação de fragilidade.

Ao longo de sua trajetória, o personagem Cobrador vai matando pessoas sempre afirmando que estão the devendo, mas seu campo de atuação fica vago à medida que não define exatamente quem são suas vítimas. Sua vingança se torna utópica já que parece desejar exterminar uma classe social inteira: a dos ricos. Para o personagem, todo o mal da humanidade é causado por eles. Seu pensamento estabelece uma dicotomia inflexível: de um lado os pobres "bonzinhos" que tentam levar a vida honestamente e de outro os ricos "malvados" que exploram e oprimem os pobres, usando força de trabalho desses para enriquecer cada vez mais.

Para o personagem Cobrador, o mal do ser humano está centrado na questão econômica, e ele seria o justiceiro dos oprimidos. Porém não há organização, nem estratégia em suas ações; trata-se de uma revolução precária de alguém que deseja algo impossível. Em seu egocentrismo, o personagem Cobrador enxerga a si próprio como uma espécie de "Messias" que veio para salvar o mundo. Mas seu desejo maior é se tornar famoso, quase uma celebridade, à medida que deseja realizar o grande feito 
de transformar a sociedade em uma organização justa. Porém há falta de articulação necessária com outros grupos para sua revolução; afinal revolução é algo que pede coletividade. Sobre isso VIDAL $[\mathrm{x}]$ afirma que: “Na verdade há na obra de Rubem Fonseca essa preocupação em retratar os humilhados e ofendidos, de cujo espaço estão ausentes os grupos organizados". A criação de sindicatos, de partidos políticos, enfim, de associações de pessoas por uma causa, que estavam em ascensão na época em que o conto foi escrito, não se refletem em seu personagem principal.

Ana será imprescindível para seu parceiro já que representa para o Cobrador a conquista de um direito readquirido, amar e ser amado. É o elo com a outra realidade. A partir do relacionamento entre eles, nasce a união que deveria existir entre os dois grupos sociais. Quando os dois se unem em busca de um único objetivo: exterminar aqueles que roubaram o direito de viver de outras pessoas menos favorecidas. Eles ganham muita força e o que antes era só um sonho, agora vira um destino, apesar de completamente inverossímil. Ana será a companheira perfeita para essa revolução quase individual e utópica, a versão feminina do cobrador: a "cobradora".

\section{REFERÊNCIAS}

COUTINHO, Afrânio. O erotismo na Literatura: o caso Rubem Fonseca. Rio de Janeiro: Cátedra, 1979.

DURIGAN, Jesus Antônio. Erotismo e Literatura. São Paulo: Ática, 1985.

FANINI, Ângela. $O$ amor e a violência em A grande Arte: uma abordagem Estético-Sociológica. Curitiba, 1991. Dissertação - UFPR.

FONSECA, Rubem. O Cobrador. Rio de Janeiro: Nova Fronteira, 1979.

Feliz Ano Novo. São Paulo: Companhia das Letras, 1989.

A grande arte. Rio de Janeiro: Francisco Alves, 1983.

$\overline{F O N T E S}$, Virgínia Maria e MENDONÇA, Sônia Regina de. História do Brasil recente: 1964 a 1992. São Paulo: Ática, 1996.

HABERT, Nadine. A década de 70. São Paulo: Ática, 1992.

LUCAS, Fábio. Situação do conto. In: $\mathbf{O}$ caráter social da Literatura Brasileira. São Paulo: Edições Quiron, 1996.

MARTÍNEZ, Tomás Eloy. A sinfonia do mal. In: FONSECA, Rubem. 64 contos/ Rubem

Fonseca. São Paulo: Companhia das Letras, 2004.

OLIVEN, Ruben George. Violência e cultura no Brasil. Petrópolis. Vozes, 1982.

PESSOA, Fernando. Poesias. Porto Alegre: L\&PM, 1999.

SILVA, Deonísio da. Rubem Fonseca: Proibido e consagrado. Rio de Janeiro: Relume-Dumará, 1996.

SILVERMAN, Malcolm. Moderna Ficção Brasileira. volume 2. Rio de Janeiro: Civilização Brasileira, 1981. In: A sátira na ficção de Rubem Fonseca. P.261-277. VIANNA, Luiz Fernando. Rubem Fonseca. Folha

[i] FONSECA, Rubem. O cobrador. Rio de Janeiro: Nova Fronteira, 1979. Doravante, as citações dessa obra se referem a essa edição e virão identificadas pela abreviatura OC e respectiva página.

[iil COUTINHO, 1979, p.35

[iiil SILVA, 1996.

[iv] MARTINEZ, 2004, p.10.

[v] SILVERMAN, 1981, p. 262. 
[vi] MARTINEZ, 2004, p.10.

[vii] PESSOA, 1999, p.83.

[viii] COUTINHO, 1979, p.27.

[ix] COUTINHO, Afrânio. O erotismo na Literatura: o caso Rubem Fonseca. Rio de Janeiro: Cátedra, 1979.

$\underline{[\mathrm{x}]}$ VIDAL, 2000, p.142. 